NOGUEIRA, T.Q. e POGGIANI, S.S.C. Hipertensão sistêmica associada à doença renal crônica, revisão de literatura. PUBVET, Londrina, V. 7, N. 1, Ed. 224, Art. 1484, 2013.

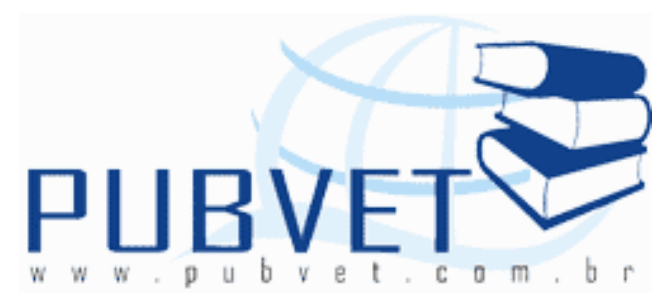

PUBVET, Publicações em Medicina Veterinária e Zootecnia.

\title{
Hipertensão sistêmica associada à doença renal crônica Revisão de literatura
}

Thaíssa Quintas Nogueira ${ }^{1}$ e Sabrina dos Santos Costa Poggiani ${ }^{2}$

\begin{abstract}
${ }^{1}$ Médica Veterinária
2 M.V., MsC, PhD, Professora do Departamento de Medicina Veterinária, Faculdades Integradas, União Pioneira de Integração Social
\end{abstract}

\section{Resumo}

O rim exerce diversas funções importantes para a manutenção da homeostase do organismo, dentre elas está a regulação da pressão sanguínea arterial. A doença renal crônica é a causa mais comum de elevação da pressão sanguínea, e, consequentemente, da hipertensão arterial em cães e gatos. Devido a essa íntima relação entre pressão arterial e função renal, o presente trabalho tem como objetivo discutir a associação entre a hipertensão arterial sistêmica e a doença renal crônica, abordando a fisiopatogenia desta alteração, suas possíveis complicações e seus aspectos diagnósticos e terapêuticos. 
NOGUEIRA, T.Q. e POGGIANI, S.S.C. Hipertensão sistêmica associada à doença renal crônica, revisão de literatura. PUBVET, Londrina, V. 7, N. 1, Ed. 224, Art. 1484, 2013.

\title{
Systemic hypertension associated with chronic kidney disease Literature review
}

\begin{abstract}
Kidneys have several important functions for the maintenance of homeostasis of the organism, among them is the regulation of arterial blood pressure. Chronic kidney disease is the most common cause of high blood pressure, and hence of hypertension in dogs and cats. Due to this close relationship between blood pressure and renal function, this paper aims to discuss the association between hypertension and chronic kidney disease, addressing the pathophysiology of this disease, its complications and its diagnostic and therapeutic aspects.
\end{abstract}

\section{Introdução}

A adequada perfusão sanguínea dos tecidos é o que garante a sobrevivência das células e, portanto a manutenção da vida. Fisiologicamente, o que assegura a perfusão tecidual é a manutenção da pressão sanguínea arterial de forma estável, isto é, através de mecanismos regulatórios a pressão é mantida em níveis aceitáveis que permitem que todos os tecidos sejam devidamente perfundidos. A pressão arterial é regulada por mecanismos nervosos, endócrinos, cardiovasculares e renais. Dessa forma, afecções que afetam esses mecanismos podem resultar em alterações pressóricas, como a hipotensão e a hipertensão.

O rim é um órgão que exerce diversas funções importantes para a manutenção da homeostase do organismo, dentre elas está a regulação da pressão sanguínea arterial. Assim, o paciente com doença renal crônica possui predisposição a desenvolver modificações na pressão sanguínea, principalmente a hipertensão. Devido a essa íntima relação entre pressão arterial e função renal, o presente trabalho tem como objetivo discutir a associação entre a hipertensão arterial sistêmica e a doença renal crônica. 
NOGUEIRA, T.Q. e POGGIANI, S.S.C. Hipertensão sistêmica associada à doença renal crônica, revisão de literatura. PUBVET, Londrina, V. 7, N. 1, Ed. 224, Art. 1484, 2013.

\section{Pressão arterial sistêmica}

A pressão arterial sistêmica consiste na pressão exercida pelo sangue sobre a superfície interna do vaso arterial (FEITOSA, 2008) e possui relação direta com a preservação do fluxo sanguíneo e da perfusão tecidual. O controle da pressão arterial depende da relação entre o débito cardíaco e a resistência vascular periférica (CUNNINGHAM, 1999). Em situações onde o aumento de uma dessas variáveis está presente, a conseqüência é o aumento da pressão arterial, conhecida como hipertensão arterial sistêmica (NELSON e COUTO, 2009). Assim sendo, hipertensão arterial pode ser definida como o aumento contínuo da pressão, que pode levar a lesões vasculares e de órgãos como coração, sistema nervoso central, olhos e o próprio rim (BOVEE, 2003).

Segundo Eaton e Pooler (2006), o controle da regulação da pressão sanguínea ocorre a curto, médio e longo prazo. A regulação a curto prazo é controlada principalmente pela atuação do sistema nervoso simpático, mais precisamente pelo centro vasomotor, localizado no bulbo. Este centro transmite, através das fibras nervosas simpáticas, impulsos simpáticos, e pelo nervo vago, impulsos parassimpáticos, ambos até o coração. Além disso, pela medula espinhal e pelos nervos periféricos, transmite impulsos simpáticos para praticamente todas as artérias, arteríolas e veias do corpo (GUYTON e HALL, 2006).

Os barorreceptores arteriais estão localizados nas artérias carótidas, mais especificamente no seio carotídeo, e também na parede interna do arco aórtico (CUNNINGHAM, 1999). Além dos barorreceptores, há também os quimiorreceptores, que estão localizados no corpo carotídeo e no corpo aórtico. Estes são compostos por células sensíveis à diminuição da concentração de oxigênio e ao excesso de dióxido de carbono e de íons de hidrogênio. Quando nessas situações, fibras nervosas são excitadas transmitindo o sinal até o centro vasomotor, que então elevará a pressão arterial de volta ao normal. Dessa forma, 
NOGUEIRA, T.Q. e POGGIANI, S.S.C. Hipertensão sistêmica associada à doença renal crônica, revisão de literatura. PUBVET, Londrina, V. 7, N. 1, Ed. 224, Art. 1484, 2013.

os quimiorreceptores têm maior importância em situações onde há uma diminuição da pressão arterial (GUYTON e HALL, 2006).

Com a percepção na modificação da pressão, sinais neuronais são enviados até o centro vasomotor através de neurônios aferentes, e este então envia sinais regulatórios via sistema nervoso autônomo para os principais sistemas efetores, dentre eles o coração, os vasos sanguíneos e os rins (EATON e POOLER, 2006). Assim, o sistema nervoso simpático é estimulado quando ocorre uma diminuição da pressão sanguínea, o que provoca vasoconstrição reflexa e estimula a liberação de catecolaminas (epinefrina e norepinefrina) pela glândula adrenal (LOSCALZO, 2010).

Os principais receptores adrenérgicos são os receptores alfa e beta. Os receptores alfa são divididos em alfa-1 e alfa-2, sendo que ambos são mais sensíveis à norepinefrina que à epinefrina. $O$ receptor alfa-1, quando estimulado, provoca principalmente vasoconstrição, enquanto que o alfa-2 promove feed-back negativo impedindo maior liberação de norepinefrina. Já os beta-receptores são mais ativados pela ação da epinefrina que pela ação da norepinefrina, e também são subdivididos em beta-1 e beta-2. Os receptores beta-1, quando estimulados, provocam o aumento da freqüência cardíaca e da contratilidade miocárdica, além de também estimularem a liberação de renina pelos rins. Os receptores beta-2 provocam vasodilatação quando estimulados pela norepinefrina, tendo então um efeito contrário importante na regulação desse mecanismo (LOSCALZO, 2010). Portanto, as principais modificações efetuadas pelo centro vasomotor são a vasodilatação e vasoconstrição das arteríolas e veias, o que modifica a resistência vascular periférica e dessa forma influencia na pressão arterial (EATON e POOLER, 2006).

A regulação da pressão à médio prazo é estabelecida principalmente pela função renal. $O$ aparelho justaglomerular é uma área presente em todos os néfrons, localizado próximo às arteríolas aferente e eferente, e tem papel 
NOGUEIRA, T.Q. e POGGIANI, S.S.C. Hipertensão sistêmica associada à doença renal crônica, revisão de literatura. PUBVET, Londrina, V. 7, N. 1, Ed. 224, Art. 1484, 2013.

importante no controle da pressão sanguínea. As células granulares, também conhecidas como barorreceptores intrarrenais, são um dos componentes do aparelho justaglomerular e são capazes de reconhecer alterações de pressão nas arteríolas aferentes renais. Estímulos nervosos originados do centro vasomotor em resposta à ativação dos barorreceptores vasculares chegam às células granulares através do nervo simpático renal (EATON e POOLER, 2006). As células granulares sintetizam e armazenam uma enzima protéica chamada renina (RIGATTO, BOHLKE e IRIGOYEN, 2004). Segundo Loscalzo (2010), os três principais estímulos para liberação da renina são a diminuição da concentração de cloreto de sódio $(\mathrm{NaCl})$ na superfície das células da mácula densa, a diminuição da pressão da arteríola aferente percebida pelas células granulares e a ativação dos receptores beta-1 adrenérgicos nas células granulares via nervos simpáticos.

A partir da liberação da renina, uma cascata de eventos bioquímicos é desencadeada, o que é conhecido como sistema renina-angiotensina-aldosterona. Este sistema contribui para a regulação da pressão arterial, pois, primeiramente, produz a angiotensina II, que é uma substância vasoativa com propriedade vasoconstritora muito potente, e também estimula a produção de aldosterona, um mineralocorticóide capaz de promover maior retenção de sódio no organismo (LOSCALZO, 2010). Quando algum dos estímulos citados anteriormente está presente, as células granulares secretam renina dando início à primeira etapa da cascata, que consiste na ação desta enzima sobre um peptídeo produzido no fígado conhecido como angiotensinogênio, dando origem a angiotensina I (EATON e POOLER, 2006). A angiotensina I possui leve propriedade vasoconstritora, porém sem atuação significativa na função circulatória (GUYTON e HALL, 2006). Após a formação da angiotensina I, outro evento enzimático mediado pela enzima conversora de angiotensina (ECA) ocorre, transformando a mesma em angiotensina II. Segundo Rigatto, Böhlke e Irigoyen (2004), além da propriedade de transformação de angiotensina I em angiotensina II, essa enzima também 
NOGUEIRA, T.Q. e POGGIANI, S.S.C. Hipertensão sistêmica associada à doença renal crônica, revisão de literatura. PUBVET, Londrina, V. 7, N. 1, Ed. 224, Art. 1484, 2013.

promove a inativação de cininas, sendo outro mecanismo que atua na vasoconstrição.

A angiotensina II é o produto final do sistema enzimático, caracterizada pela sua potente função vasoconstritora, o que provoca o aumento da resistência vascular periférica e da pressão sanguínea (EATON e POOLER, 2006). A angiotensina II também regula a pressão sanguínea de duas outras maneiras: modulando a reabsorção de sódio e água nos túbulos renais (forma indireta) e estimulando a produção e liberação de aldosterona pelo córtex da adrenal (forma direta), o que eleva lentamente o volume do líquido extracelular e consequentemente a pressão arterial. Nos rins, devido à sua maior predileção pela arteríola aferente, a angiontesina II promove o aumento da pressão intraglomerular ao elevar a resistência vascular (LEFEBVRE e TOUTAIN, 2004), consequentemente aumentando também a taxa de filtração glomerular (RENNKE e DENKER, 2009).

Segundo Loscalzo (2010), o angiotensinogênio, a renina e a angiotensina podem ser também sintetizadas em outros locais, o que sugere a existência de sistemas renina-angiotensina teciduais, distribuídos em diferentes órgãos como o coração, vasos sanguíneos, cérebro, hipófise, adrenal, pele, ovários, testículos, baço, e células como adipócitos e leucócitos. Estudos têm demonstrado a existência de vias alternativas de formação de angiotensina II, isto é, a angiotensina II sendo formada não só através da ação da ECA, mas também pela ação de outras proteases teciduais, como a tonina, catepsina $G$ e a quimase (MILL e RESENDE, 2002). Além de auxiliar na regulação do fluxo sanguíneo local, a angiotensina II tecidual também possui ação mitogênica, estimulando o crescimento e a reparação celular (LOSCALZO, 2010).

Por fim, a manutenção da pressão sanguínea a longo prazo está intimamente relacionada à homeostasia dos líquidos corporais, isto é, ao equilíbrio entre a ingestão e a excreção de líquidos. Este controle é exercido 
NOGUEIRA, T.Q. e POGGIANI, S.S.C. Hipertensão sistêmica associada à doença renal crônica, revisão de literatura. PUBVET, Londrina, V. 7, N. 1, Ed. 224, Art. 1484, 2013.

basicamente por fatores intrínsicos da função renal e são determinantes para a manutenção adequada da pressão arterial (GUYTON e HALL, 2010).

$O$ aumento da pressão sanguínea percebida pelos barorreceptores intrarenais é interpretada tanto como o aumento do volume plasmático quanto como o aumento do sódio plasmático (EATON e POOLER, 2006), diante disso, mecanismos renais se tornam ativos a fim de promover uma compensação do volume circulatório, conhecidos como diurese e natriurese pressóricas. Essa integração entre os rins e o sistema circulatório tem participação dominante na regulação da pressão arterial a longo prazo. Diurese pressórica consiste no aumento do débito urinário, isto é, maior excreção de água, resultante da elevação da pressão arterial (GUYTON e HALL, 2010). Este mecanismo compensatório está intimamente relacionado a outro, a natriurese pressórica, que consiste no aumento da excreção de sódio devido à redução da reabsorção de sódio pelos túbulos renais (EATON e POOLER, 2006). Segundo Loscalzo (2010), a natriurese por pressão envolve o aumento da taxa de filtração glomerular, diminuição da capacidade de reabsorção de sódio pelos túbulos renais e possível atuação do peptídeo natriurético atrial.

A aldosterona é um mineralocorticóide que tem como importante função a elevação acentuada da reabsorção de sódio pelos túbulos renais (GUYTON e HALL, 2010). Segundo Rennke e Denker (2009), o principal sítio de ação da aldosterona se localiza nas células do ducto coletor cortical, onde ela promoverá basicamente a reabsorção de $\mathrm{NaCl}$ e a excreção de potássio. Eaton e Pooler (2006) afirmam que os dois principais sinais que chegam à glândula adrenal e que determinam o estímulo à síntese desse hormônio são a presença de angiotensina II e o aumento da concentração plasmática de potássio. Guyton e Hall (2006) enfatizam essa afirmação ao relatar que em situações onde o sistema renina-angiotensina está ativo, os níveis de aldosterona também estão elevados. 
NOGUEIRA, T.Q. e POGGIANI, S.S.C. Hipertensão sistêmica associada à doença renal crônica, revisão de literatura. PUBVET, Londrina, V. 7, N. 1, Ed. 224, Art. 1484, 2013.

Segundo Nelson e Couto (2009), tanto a angiotensina quanto a aldosterona são substâncias pró-inflamatórias. A angiotensina II promove o aumento da produção de Tranforming Growth Factor - beta (TGF-beta), uma poderosa citocina fibrogênica, cuja principal ação renal é estimular a produção excessiva de matriz extracelular. Além disso, sabe-se que a TGF-beta possui efeito semelhante à angiotensina II, pois é capaz de estimular a vasoconstrição da musculatura lisa (LEFEBVRE e TOUTAIN, 2004). Trapp e colaboradores (2009) citam que, quando em condições anormais, a angiotensina II possui outros efeitos deletérios além de alterar a resistência vascular e da hipertensão, como a hipertrofia de miócitos, estímulo à produção de radicais livres e outras substâncias pró-inflamatórias.

Um dos mecanismos envolvidos na ativação do SNS no doente renal crônico diz respeito à presença da angiotensina II, que além de sua ação pressórica, possui efeitos diretos na estimulação nervosa (ATKINS e GRAUER, 2007). Campese et al. (2011) relatam que o aumento do estresse oxidativo, a hipóxia renal e a redução da disponibilidade de óxido nítrico em algumas regiões específicas do cérebro, possivelmente presentes nas DRC, também são estímulos de ativação do SNS. A atividade deste sistema nos rins, além de diminuir a TFG e o fluxo sanguíneo renal, também provoca maior reabsorção de sódio e água pelos túbulos renais, o que auxilia na elevação da pressão arterial. Outro fator que comprova a participação do SNS na patogenia da hipertensão secundária a DRC, é a presença, nestes pacientes, de níveis plasmáticos aumentados de catecolaminas, como a norepinefrina (RIELLA, 2003).

Alterações de volume são percebidas também pelas fibras musculares do átrio, que ao serem distendidas, promovem a liberação do peptídeo natriurético atrial (GUYTON e HALL, 2006). Esse peptídeo possui duas funções principais que podem contribuir para a regulação do volume circulatório, são elas: promover o relaxamento da arteríola aferente e constrição da arteríola eferente, o que 
NOGUEIRA, T.Q. e POGGIANI, S.S.C. Hipertensão sistêmica associada à doença renal crônica, revisão de literatura. PUBVET, Londrina, V. 7, N. 1, Ed. 224, Art. 1484, 2013.

aumenta a taxa de filtração glomerular, e reduzir a reabsorção de sódio tubular através do fechamento direto dos canais de sódio nos túbulos coletores, o que suprime a liberação de renina pelo rim e de aldosterona pela glândula adrenal (RENNKE e DENKER, 2009). Segundo Guyton e Hall (2006), essas duas ações do peptídeo natriurético atrial promovem o aumento da excreção de sódio e de água, o que ajuda a compensar o excesso de volume circulante.

Durante o ciclo cardíaco, a pressão arterial média se mantém mais próxima à pressão diastólica que à pressão sistólica, sendo a primeira correspondente a $60 \%$ da pressão arterial média enquanto a pressão sistólica corresponde a apenas $40 \%$. Dessa forma, a pressão arterial média não pode ser estabelecida como sendo a média entre as pressões sistólica e diastólica, e sim como sendo a média das pressões arteriais medidas a cada milissegundo durante certo intervalo de tempo (GUYTON e HALL, 2006). Por outro lado, de acordo com Santos e Fragata (2008), a pressão arterial média pode ser obtida através do cálculo de pressão média durante o ciclo cardíaco completo seguindo a seguinte equação: PAM = $P A D+1 / 3$ (PAS - PAD). Isto é, a pressão arterial média (PAM) é resultado da soma da pressão arterial diastólica (PAD) com um terço da subtração entre a pressão arterial sistólica (PAS) e a pressão arterial diastólica (PAD).

A mensuração indireta (não-invasiva) e a mensuração direta (invasiva) são os dois principais métodos de determinação da pressão arterial utilizados na medicina veterinária (FEITOSA, 2008). Segundo Acierno e Labato (2005), a mensuração direta ou invasiva é o método mais preciso de mensuração da pressão sanguínea. Nelson e Couto (2009) enfatizam que a precisão e a eficácia deste método são maiores, princialmente, quando se trata de animais hipotensos. Tal procedimento consiste na introdução de um catéter heparinizado em uma artéria periférica. A mensuração se realiza através de um aparelho acoplado que pode ser tanto um manômetro como um monitor de pressão invasiva. As artérias mais comumente utilizadas são as metatársicas e a femoral (SANTOS e FRAGATA, 
NOGUEIRA, T.Q. e POGGIANI, S.S.C. Hipertensão sistêmica associada à doença renal crônica, revisão de literatura. PUBVET, Londrina, V. 7, N. 1, Ed. 224, Art. 1484, 2013.

2008); as metacárpicas e a sublingual também podem ser utilizadas (FEITOSA, 2008). Por ser um método cruento e que envolve alguns riscos como tromboembolia e hemorragia (SANTOS e FRAGATA, 2008), a mensuração invasiva é a mais indicada e utilizada na terapia intensiva veterinária. Os três métodos de mensuração não-invasiva que tem sido estudados e validados para uso em animais de pequeno porte são o Doppler, oscilométrico e fotopletismografia(ACIERNO e LABATO, 2005).

Segundo Feitosa (2008), não há uma definição de um valor único para a pressão arterial em cães, e esta varia de acordo com a raça, idade e tamanho do animal. Acierno e Labato (2005) citam o sexo e a obesidade como outros fatores que também promovem a variação destes valores. Por outro lado, Ettinger e Feldman (2010) classificam a pressão arterial sistólica normal quando esta não excede $160-170 \mathrm{mmHg}$ em um animal acordado e não estressado. Pelo método oscilométrico, a média aceitável da pressão sanguínea normal entre as raças de cães é $133 / 75 \mathrm{mmHg}$ (sistólica/diastólica) e entre os gatos é $124 / 84 \mathrm{mmHg}$ (NELSON e COUTO, 2009). A Veterinary Blood Pressure Society classificou a hipertensão como leve, moderada e severa, de acordo com os resultados obtidos em pelo menos três mensurações da pressão arterial. $O$ animal que possui valores de pressão sistólica entre $150-160 \mathrm{mmHg}$ e diastólica entre $95-100 \mathrm{mmHg}$, é diagnosticado com hipertensão leve. A hipertensão moderada está presente em animais com pressão sistólica e diastólica entre $160-180 \mathrm{mmHg}$ e $100-120 \mathrm{mmHg}$, respectivamente. A classificação para a hipertensão severa ocorre nos casos em que o animal apresenta a pressão arterial acima de $180 / 120 \mathrm{~mm} \mathrm{Hg}$ (sistólica/diastólica) (NELSON e COUTO, 2009).

Segundo Brown, Atkins e Bagley et al. (2007), a hipertensão sistêmica pode ser classificada em três categorias: hipertensão do jaleco branco (White coat effect), hipertensão primária (idiopática) e hipertensão secundária. O processo de ida ao consultório veterinário, bem como a própria mensuração da pressão 
NOGUEIRA, T.Q. e POGGIANI, S.S.C. Hipertensão sistêmica associada à doença renal crônica, revisão de literatura. PUBVET, Londrina, V. 7, N. 1, Ed. 224, Art. 1484, 2013.

arterial, pode gerar um estado de ansiedade no animal. Devido ao estresse, o sistema nervoso autônomo, mais precisamente o sistema nervoso simpático, pode ser ativado a ponto de elevar a pressão arterial sistêmica, efeito conhecido como "White coat effect" (NELSON e COUTO, 2009).

O aumento contínuo da pressão arterial associado à ausência de causas identificáveis que predisponham a essa situação, é classificada como hipertensão primária (BROWN, ATKINS e BAGLEY, 2007). Em seres humanos, a hipertensão idiopática é a causa mais comum entre os pacientes hipertensos, envolvendo cerca de $80-90 \%$ destes. Porém, em medicina veterinária, a hipertensão primária é menos comum e verifica-se uma prevalência da hipertensão secundária (MISHINA e WATANABE, 2008).

A hipertensão secundária envolve o aumento da pressão sanguínea que ocorre devido à existência de alguma doença ou condição clínica conhecida por elevar a pressão sanguínea (ACIERNO e LABATO, 2005). O uso de agentes terapêuticos como os glicocorticóides, mineralocorticóides, eritropoietina, entre outros, pode levar a hipertensão arterial que, nesse caso, também é considerada secundária (BROWN, ATKINS e BAGLEY, 2007). De acordo com Nelson e Couto (2009), as enfermidades que estão geralmente associadas com hipertensão em cães são as doenças renais, principalmente aquelas com envolvimento glomerular, e o hiperadrenocorticismo. Nos felinos, as mais associadas são a doença renal e o hipertireoidismo. O mesmo autor relata que diabetes mellitus, hipotireoidismo e doenças hepáticas também podem ter relação com o aumento da pressão arterial. Outras alterações endócrinas incomuns em cães e que estão associadas ao aumento da pressão arterial são o feocromocitoma, o hiperaldosteronismo primário e a acromegalia (BONAGURA e TWEDT, 2009).

Ettinger e Feldman (2010) reforçam que a doença renal crônica é a causa mais comum de elevação da pressão sanguínea, e, consequentemente, da hipertensão arterial em cães e gatos. Segundo Elliot e Lefebvre (2009), a doença 
NOGUEIRA, T.Q. e POGGIANI, S.S.C. Hipertensão sistêmica associada à doença renal crônica, revisão de literatura. PUBVET, Londrina, V. 7, N. 1, Ed. 224, Art. 1484, 2013.

renal crônica ocorre como conseqüência da substituição dos néfrons por tecido cicatricial fibroso, pois os mesmos não possuem capacidade regenerativa. De acordo com Junior (2004), a doença renal crônica consiste em lesão renal e perda progressiva e irreversível da função dos rins (glomerular, tubular e endócrina). Bartolotto (2008) complementa ao citar que os indícios das alterações estruturais ou funcionais provocadas pela lesão renal são observados em exames de sangue, de urina ou de imagens, e podem provocar ou não a diminuição da taxa de filtração glomerular. A insuficiência renal crônica, por sua vez, é caracterizada pela diminuição da taxa de filtração glomerular, e geralmente está presente no estágio final da doença renal crônica (DRC). Segundo Atkins e Grauer (2007), as doenças renais que mais estão associadas com o desenvolvimento da DRC são: glomerulonefrite, amiloidose, doenças tubulointersticiais, pielonefrite, nefrolitíases, doença renal policística, peritonite infecciosa felina e neoplasia.

Os exames laboratoriais realizados para avaliação renal incluem bioquímica sanguínea, hemograma e urinálise. Estes, além de auxiliar na confirmação da suspeita clínica, também podem indicar a etiologia bem como a presença de alguma doença-base (BONAGURA e TWEDT, 2009). Elliot e Lefebvre (2009) complementam ao citar que a mensuração da pressão arterial, bem como a ultrassonografia ou radiografia abdominal, também podem ser úteis no diagnóstico.

Sabe-se que as concentrações séricas de creatinina e uréia são inversamente proporcionais à taxa de filtração glomerular, por isso, as dosagens desses dois marcadores são os testes bioquímicos de triagem mais comumente realizados (ETTINGER e FELDMAN, 2010). Devido à grande capacidade de reserva dos rins, a azotemia só está presente quando há perda de pelo menos $60-70 \%$ da função renal normal (ELLIOT e LEFEBVRE, 2009).

Apesar de muitas vezes, no início da DRC, os valores de sódio, cálcio, fósforo e potássio estarem normais ou próximos ao normal, a dosagem destes 
NOGUEIRA, T.Q. e POGGIANI, S.S.C. Hipertensão sistêmica associada à doença renal crônica, revisão de literatura. PUBVET, Londrina, V. 7, N. 1, Ed. 224, Art. 1484, 2013.

eletrólitos pode ser uma ferramenta importante para o diagnóstico (DRAIBE e CENDOROGLO, 2001). Segundo Elliot e Lefebvre (2009), as alterações mais observadas são hiperfosfatemia, hipocalemia, hipocalcemia (às vezes, hipercalcemia) e hiponatremia. No trabalho realizado por Martínez e Carvalho (2010), onde a excreção renal e o perfil sérico de cálcio, sódio, fósforo e potássio foram avaliados em cães sadios e com doença renal crônica, concluiu-se que a avaliação da excreção renal destes principais eletrólitos pode evidenciar déficit da função renal mesmo nos estágios iniciais da DRC, e, portanto pode ser empregada como meio de diagnóstico precoce da doença.

Outro importante marcador da DRC é a presença de proteinúria persistente de origem renal (MARTÍNEZ e CARVALHO, 2010). De acordo com a International Renal Interest Society (IRIS), um forte indicativo de doença glomerular é a presença de proteinúria persistente, associada a sedimento urinário normal e presença de cilindros hialinos, porém ressalva que a proteinúria também pode estar presente em quando só houve lesão dos glomérulos. A IRIS também afirma que o cálculo onde se estabelece a relação entre a creatinina e a proteína urinárias (RPC) através da amostra de urina de cães e gatos permite definir com precisão a quantidade de proteína excretada na urina durante um período de 24 horas. O cálculo consiste na divisão da concentração total de proteína urinária pela concentração de creatinina urinária (LEES, 2004). O valor normal de RPC em cães e gatos segundo Ettinger e Feldman (2010) é quando este é menor que 0.4.

Uma das etapas da urinálise consiste na mensuração da densidade urinária através de um refratômetro, que é capaz de quantificar a concentração de soluto na urina. Segundo a IRIS, a densidade urinária normal em cães pode variar de 1.001 a maior que 1.075, enquanto em gatos de 1.001 a maior que 1.085 . Porém, Feitosa (2008) cita que o intervalo de variação mais comum da densidade urinária para cães está entre 1.013 e 1.035. O termo isostenúria se refere à urina que possui a mesma quantidade de soluto que o filtrado glomerular (1.007 - 
NOGUEIRA, T.Q. e POGGIANI, S.S.C. Hipertensão sistêmica associada à doença renal crônica, revisão de literatura. PUBVET, Londrina, V. 7, N. 1, Ed. 224, Art. 1484, 2013.

1.015), hipostenúria à que possui quantidade menor de soluto quando comparado ao filtrado glomerular $(<1.007)$ e hiperstenúria à urina que possui concentração de soluto maior que o filtrado glomerular (>1.015) (ETTINGER e FELDMAN, 2010). A incapacidade dos rins de concentrar a urina (isostenúria) ocorre devido à diminuição do número de néfrons, pois os mecanismos normais de concentração e diluição não funcionam adequadamente na DRC (GUYTON e HALL, 2010).

O sistema de estadiamento da doença renal crônica foi desenvolvido, em 2009, pela International Renal Interest Society (IRIS). Este sistema visa facilitar a implementação do tratamento ideal e adequado acompanhamento do paciente. O estadiamento é inicialmente baseado na dosagem da creatinina plasmática com o animal em jejum, avaliada em pelo menos duas ocasiões (Tabela 1).

Tabela 1: Estadiamento da DRC segundo valores plasmáticos de creatinina

\begin{tabular}{c|c|c|}
\hline Estágio & \multicolumn{2}{|c|}{ Valores Creatinina Plasmática $\mathbf{( m g / d L )}$} \\
\hline & Cães & Gatos \\
\hline Estágio 1 & $<1.4$ & $<1.6$ \\
Estágio 2 & $1.4-2.0$ & $1.6-2.8$ \\
Estágio 3 & $2.1-5.0$ & $2.9-5.0$ \\
Estágio 4 & $>5.0$ & $>5.0$ \\
\hline
\end{tabular}

O estágio 1 da DRC inclui cães e gatos com DRC não-azotêmicos, enquanto o estágio 2 inclui cães e gatos com leve azotemia. Os animais que se encontram nesses dois estágios comumente não apresentam sinais clínicos da disfunção renal, com exceção da poliúria e polidipsia que podem estar presentes (ETTINGER e FELDMAN, 2010). A IRIS também comenta que os animais em estágio 1, apesar de não apresentarem azotemia, podem ter outras anormalidades renais presentes como: inadequada habilidade de concentração urinária sem outras causas não- 
NOGUEIRA, T.Q. e POGGIANI, S.S.C. Hipertensão sistêmica associada à doença renal crônica, revisão de literatura. PUBVET, Londrina, V. 7, N. 1, Ed. 224, Art. 1484, 2013.

renais identificáveis, palpação renal anormal ou achados radiográficos anormais, proteinúria de origem renal, resultado de biópsia com alterações e elevação progressiva dos níveis de creatinina.

Segundo a IRIS, cães e gatos que apresentam azotemia moderada são classificados como estágio 3 da DRC. Nesse estágio os animais podem apresentar sinais clínicos referentes à perda da função renal. E por fim, animais no estágio 4 são aqueles que apresentam severa azotemia, que está frequentemente associada com a presença de sinais clínicos da uremia.

Posteriormente, ainda de acordo com a IRIS, o subestadiamento é feito com base na proteinúria e pressão arterial sistêmica do animal (Tabela 2).

Tabela 2: Estadiamento da DRC segundo valores de RPC

\begin{tabular}{c|c|c}
\hline \multicolumn{2}{c|}{ Valores de UPC } & Subestadiamento \\
\hline Cães & Gatos & \multirow{2}{*}{ Não proteinúrico } \\
\hline$<0.2$ & $<0.2$ & Limítrofe proteinúrico \\
$0.2-0.5$ & $0.2-0.4$ & Proteinúrico \\
$>0.5$ & $>0.4$ & \\
\hline
\end{tabular}

O subestadiamento através da pressão sanguínea é feito pela avaliação do risco de lesão de órgãos-alvo e se já há ou não evidências clínicas dessas lesões. Os riscos de lesão de órgãos-alvo classificam-se em risco mínimo (estágio 0), baixo risco (estágio 1), risco moderado (estágio 2) e alto risco (estágio 3). Em relação à presença de lesões em órgãos, classifica-se em sem complicações e com complicações, onde a primeira refere-se aos animais que não apresentam evidências de lesões em órgãos e, a segunda, aos animais que já apresentam essas lesões. $O$ animal que apresenta pressão arterial persistente na classificação de risco moderado (estágio 2) ou alto risco (estágio 3), em três ocasiões em pelo 
NOGUEIRA, T.Q. e POGGIANI, S.S.C. Hipertensão sistêmica associada à doença renal crônica, revisão de literatura. PUBVET, Londrina, V. 7, N. 1, Ed. 224, Art. 1484, 2013.

menos 2 semanas, é sugerida intervenção terapêutica, mesmo que lesões de órgãos-alvo ainda não estejam aparentes (Tabela 3).

Tabela 3: Estadiamento da DRC segundo valores da pressão arterial sistêmica

\begin{tabular}{c|c|c}
\hline Subestadiamento & PAS & PAD \\
\hline Estágio 0 & $<150 \mathrm{~mm} \mathrm{Hg}$ & $<95 \mathrm{~mm} \mathrm{Hg}$ \\
Estágio 1 & $150-159 \mathrm{~mm} \mathrm{Hg}$ & $95-99 \mathrm{~mm} \mathrm{Hg}$ \\
Estágio 2 & $160-179 \mathrm{~mm} \mathrm{Hg}$ & $100-119 \mathrm{~mm} \mathrm{Hg}$ \\
Estágio 3 & $\geq 180 \mathrm{~mm} \mathrm{Hg}$ & $\geq 120 \mathrm{~mm} \mathrm{Hg}$ \\
\hline
\end{tabular}

De acordo com Rennke e Denker (2009), a taxa de filtração glomerular (TFG) é a soma da filtração de todos os néfrons viáveis e funciona como um marcador da massa renal funcional. Independente do tipo de lesão inicial, com o decorrer da doença, todas as estruturas presentes nos néfrons (glomérulos, túbulos e interstícios) são afetadas, culminando na diminuição do número de néfrons funcionais e da TFG (MARTÍNEZ e CARVALHO, 2010). A redução da TFG ocasionada pela doença renal provoca uma inabilidade dos rins de manter a composição normal do líquido extracelular, sendo os compostos nitrogenados as primeiras substâncias a terem suas concentrações (aumentadas) (LEES, 2004). Creatinina, uréia, renina, fosfatos, amônia, gastrina, entre outros, são algumas das substâncias que possuem a excreção renal como principal forma de eliminação do organismo e, portanto, nessas situações, têm suas concentrações plasmáticas aumentadas (NELSON e COUTO, 2009).

Quando os néfrons lesionados se tornam essencialmente afuncionais, os néfrons remanescentes, através de um processo compensatório, sofrem hipertrofia a fim de manter a função renal adequada, fenômeno explicado através da Teoria da Hiperfiltração (ELLIOT e LEFEBVRE, 2009). Apesar de essas alterações adaptativas terem efeitos benéficos por, inicialmente, aumentarem a 
NOGUEIRA, T.Q. e POGGIANI, S.S.C. Hipertensão sistêmica associada à doença renal crônica, revisão de literatura. PUBVET, Londrina, V. 7, N. 1, Ed. 224, Art. 1484, 2013.

taxa de filtração glomerular, elas também causam injúria glomerular como a glomeruloesclerose, o que auxilia na progressão da doença (BONAGURA e TWEDT, 2009). Segundo Draibe e Cendoroglo (2001), o glomérulo é a porção dos néfrons funcionais que mais sofre essa alteração morfológica (hipertrofia). Greenberg et al. (2009) explica que isso ocorre devido à diminuição do tônus da arteríola aferente, quando comparado com a arteríola eferente. Como conseqüência, a pressão intraglomerular e a quantidade de filtrado produzido por cada néfron aumentam - em outras palavras, ocorre a hiperfiltração glomerular. Para White et al. (2010), a hipertensão glomerular é uma das alterações importantes para a progressão da DRC, pois, de acordo com Ettinger e Feldman (2010), leva a lesão celular e a desarranjos estruturais e funcionais. As alterações morfológicas e funcionais desencadeiam o surgimento da proteinúria, o que provoca um intenso fluxo de proteínas pelos túbulos renais. Esse intenso fluxo é lesivo às estruturas tubulares, pois estimula a produção local de substâncias, hormônios, citocinas inflamatórias e fatores de crescimento como, angiotensina II, Fator de Necrose Tumoral (FNT), Platelet-Derived Growth Factor (PDGF) e Transforming Growth Factor (TGF-beta) (DRAIBE e CENDEROGLO, 2001). Segundo Greenberg e Cheung et al. (2009), a ativação dessa variedade de moléculas pode resultar no acúmulo anormal de colágeno e de outros componentes na matriz extracelular, que podem ser responsáveis pela fibrose intersticial.

A doença renal crônica é uma enfermidade relativamente frequente em animais de pequeno porte, e é também a causa mais comum de hipertensão nos mesmos. Apesar da dificuldade em se estabelecer a prevalência da hipertensão como conseqüência da doença renal crônica, estudos sugerem que esta seja maior que $60 \%$ (CARR e EGNER, 2009). Porém, um estudo realizado por Buranakarl et al. (2007) demonstrou que em 30 cães azotêmicos apenas 20\% apresentavam hipertensão, e que geralmente lesões renais leves não estão 
NOGUEIRA, T.Q. e POGGIANI, S.S.C. Hipertensão sistêmica associada à doença renal crônica, revisão de literatura. PUBVET, Londrina, V. 7, N. 1, Ed. 224, Art. 1484, 2013.

associadas com a elevação da pressão sanguínea. Este trabalho relata que não há relação entre o grau de insuficiência renal - avaliado através da concentração plasmática de creatinina -, e hipertensão.

Segundo Kossi et al. (2009), a hipertensão é o fator de risco mais importante associado com o acelerado declínio da função renal nos pacientes com DRC, e o seu controle é a forma mais efetiva de evitar a progressão. Isso provavelmente se deve à contribuição que a hipertensão tem na perda progressiva de néfrons por causar lesão glomerular através do aumento da pressão intraglomerular e glomeruloesclerose. Um processo conhecido como "auto-regulação renal" permite manter a pressão nos capilares glomerulares relativamente estável mesmo diante de alterações na pressão arterial sistêmica, através de mudanças na resistência da arteríola aferente. Porém, no paciente com DRC este mecanismo de proteção não é efetivo. Dessa forma, uma dilatação inapropriada da arteríola aferente ocorre, o que diminui a habilidade da mesma de proteger os capilares glomerulares das alterações de pressão sistêmica que podem ocorrer (ATKINS e GRAUER, 2007).

Com o declínio da TFG, cada néfron remanescente aumenta substancialmente a carga de excreção de eletrólitos e água. Apesar da notável capacidade dos rins em manter o equilíbrio hidro-eletrolítico, nos estágios mais avançados da doença renal crônica (DRC), esses mecanismos compensatórios não funcionam adequadamente (ETTINGER e FELDMAN, 2010). Quando nestas situações, a diminuição do ritmo da filtração glomerular provoca a diminuição da capacidade de excretar sódio e água. Conseqüentemente, ocorre expansão do liquido extracelular e aumento do débito cardíaco, que por fim eleva a pressão arterial sistêmica (RIELLA, 2003).

Devido a uma diminuição da reabsorção tubular, a excreção urinária de várias substâncias pode ser mantida de maneira normal mesmo na presença da redução da TFG. No entanto, quando na DRC, mesmo que a ingestão de sal 
NOGUEIRA, T.Q. e POGGIANI, S.S.C. Hipertensão sistêmica associada à doença renal crônica, revisão de literatura. PUBVET, Londrina, V. 7, N. 1, Ed. 224, Art. 1484, 2013.

permaneça a mesma, observa-se uma diminuição da reabsorção tubular de sódio. Isso é explicado pela possível existência de uma substância circulante com atividade natriurética, que contribui para a regulação do aumento da excreção de sódio por néfron. Essa substância, conhecida como digitalis-like, está presente quando ocorre expansão do volume circulatório e atua inibindo a bomba de sódio e potássio (BOURGOIGNIE, 1972). Buckalew et al. (1984) comprovou a existência dessa mesma substância no plasma de cães.

Riella (2003) cita que a disfunção no endotélio vascular pode ser um dos mecanismos que participam da patogênese da hipertensão na doença renal crônica, por aumento da produção de substâncias vasoconstritoras e diminuição de vasodilatadoras. Dentre as funções renais fisiológicas estão a produção de substâncias potencialmente hipotensoras como as prostaglandinas renais, calicreínas e óxido nítrico, que possuem ação vasodilatadora (WORONIK, 1998).

O óxido nítrico é uma substância produzida pelo endotélio vascular que possui ação vasodilatadora e assim é capaz de diminuir a resistência vascular renal (GUYTON e HALL, 2006). É conhecida a existência de outra substância que inibe, por competição, a óxido nítrico sintase - enzima responsável pela síntese de óxido nítrico. Fisiologicamente, a eliminação desta substância do organismo se dá através da excreção renal. Nos pacientes com DRC, essa excreção não ocorre adequadamente, o que provoca o acúmulo da mesma no organismo, e conseqüentemente a inibição do óxido nítrico (HEIMANN et al., 2002).

A endotelina é uma substância também produzida pelas células endoteliais, conhecida principalmente pelo seu efeito vasoconstritor sistêmico e renal. Porém, sabe-se que a endotelina também tem influência no transporte de fluidos e eletrólitos, estimula a liberação de aldosterona, renina e catecolaminas, além de possuir efeito mitogênico e pró-inflamatório (ZATZ, 2000). Segundo Castro (1996), os pacientes com DRC possuem as concentrações desse peptídeo elevadas no plasma. Apesar de alguns trabalhos sugerirem correlação entre a 
NOGUEIRA, T.Q. e POGGIANI, S.S.C. Hipertensão sistêmica associada à doença renal crônica, revisão de literatura. PUBVET, Londrina, V. 7, N. 1, Ed. 224, Art. 1484, 2013.

presença de endotelina e o aumento da pressão arterial, a sua relação com a ocorrência de hipertensão nos pacientes com DRC ainda não foi totalmente elucidada (WORONIK, 1998). Porém Carvalho et al. (2001), citam a endotelina como sendo um dos fatores contráteis gerados pelo endotélio vascular, e que, portanto, contribui nos efeitos causados pela disfunção endotelial na hipertensão.

Recentemente, uma enzima secretada pelos rins chamada renalase foi descoberta. Sua ação consiste na metabolização de catecolaminas, sendo a dopamina a metabolizada com maior eficiência, seguida pela epinefrina e norepinefrina (LI, XU e WANG et al., 2008). Pacientes com DRC em estágio final apresentam concentração reduzida desta substância circulante no sangue (BOOMSMA e TIPTON, 2007; LI, XU e WANG et al., 2008). Segundo Xu e Li (2005), a redução dos níveis circulantes de renalase se deve às anormalidades metabólicas associadas com a insuficiência renal crônica, isto é, ao estado urêmico. Considerando-se o fato de que estes pacientes já possuem níveis elevados de catecolaminas circulantes, acredita-se que a concentração baixa de renalase acentue ainda mais esta situação, o que pode contribuir para o desenvolvimento da hipertensão (XU, LI e WANG et al., 2005).

O sistema cinina-calicreína é composto por enzimas, cujos principais componentes são a enzima calicreína, o cininogênio, as cininas (bradicinina e lisilbradicinina) e as cininases. As cininas são o substrato final desta cascata enzimática e possuem basicamente função vasodilatadora (ZATZ, 2000). Levinsky (1979) relata que a excreção de calicreína encontra-se possivelmente aumentada em pacientes nefropatas, o que contribui para a redução dos níveis de cininas circulantes. Uma vez que essa redução pode contribuir para a retenção de sódio, e diminuição de substâncias vasodilatadoras circulantes, esse sistema parece influenciar na patogenia da hipertensão (ZATZ, 2000).

A existência de uma pressão sanguínea constantemente elevada como visto na hipertensão, pode causar injúria a diversos tecidos. Segundo Atkins e Grauer 
NOGUEIRA, T.Q. e POGGIANI, S.S.C. Hipertensão sistêmica associada à doença renal crônica, revisão de literatura. PUBVET, Londrina, V. 7, N. 1, Ed. 224, Art. 1484, 2013.

(2007), os órgãos mais comumente afetados são os olhos, os rins, o coração e o sistema nervoso central, conhecidos também como órgãos-alvo. Retinopatia hipertensiva e corioidopatia, manifestadas por edema de retina, vasos tortuosos, hemorragias e descolamento de retina, são manifestações comuns de hipertensão (BONAGURA e TWEDT, 2009). Os animais com hipertensão arterial podem apresentar sintomas de cegueira aguda (com pupilas fixas e dilatadas) como conseqüência do descolamento de retina (MAGGS, MILLER e OFRI, 2009).

Outra alteração que pode estar presente é a hipertrofia do músculo cardíaco que pode se manifestar através de murmúrios cardíacos, ritmo de galope na auscultação e arritmias no eletrocardiograma (BONAGURA e TWEDT, 2009). O mecanismo pelo qual a hipertrofia ocorre nestas situações é devido à resposta adaptativa que o miocárdio tem frente ao aumento da pressão sanguínea no coração. O aumento da pressão nas câmaras cardíacas faz com que, por um processo compensatório, haja um aumento da espessura da parede cardíaca, o que caracteriza a hipertrofia. O ventrículo esquerdo é a parte do coração que mais responde a essas alterações, sendo a hipertrofia mais evidente no mesmo (CARR e EGNER, 2009).

Síncope, mudanças comportamentais e demência são os sinais nervosos agudos mais observados decorrentes da hipertensão sistêmica (ETTINGER e FELDMAN, 2010). Brown e Henik (1998) citam que animais com hipertensão não controlada podem apresentar sinais clínicos compatíveis com hemorragia cerebral como inclinação de cabeça, depressão e convulsão. Além disso, acrescentam ainda que freqüentemente, nestas situações, o prognóstico é desfavorável. Os mesmos autores relatam que estes sintomas podem também estar associados ao edema cerebral provocado pela elevação da pressão hidrostática intracapilar, presente quando a hipertensão excede o limite de auto regulação.

Segundo Silva, Gonçalves, Ortega e Mion (2008), os três principais mecanismos envolvidos na patogênese da lesão renal decorrente da hipertensão 
NOGUEIRA, T.Q. e POGGIANI, S.S.C. Hipertensão sistêmica associada à doença renal crônica, revisão de literatura. PUBVET, Londrina, V. 7, N. 1, Ed. 224, Art. 1484, 2013.

são isquemia dos glomérulos decorrente do estreitamento progressivo das arteríolas aferentes, diminuição do número de néfrons - por um processo adaptativo dos néfrons remanescentes, a arteríola aferente permanece dilatada, o que permite a transmissão da hipertensão arterial sistêmica para os glomérulos, a hipertensão e a hiperfiltração glomerular até a glomeruloesclerose, e falha do mecanismo de auto-regulação renal, o que provoca uma vasodilatação da arteríola aferente e, conseqüentemente, permite a passagem da hipertensão sistêmica para os glomérulos.

Segundo a IRIS, a pressão arterial necessária para prevenir a progressão da DRC ainda não é conhecida. A primeira meta do tratamento é reduzir a pressão arterial sistólica para $<160 \mathrm{mmHg}$, e assim minimizar as chances de lesão de outros tecidos e órgãos. Porém, se não há evidências de injúria de órgãos, mas a pressão arterial sistólica persiste $>160 \mathrm{mmHg}$, o tratamento mesmo assim deve ser instituído. Os fármacos mais utilizados no tratamento anti-hipertensivo, segundo Nelson e Couto (2009), são os inibidores da ECA, os bloqueadores dos canais de cálcio e os bloqueadores beta-adrenérgicos.

A redução da pressão arterial no DRC é um objetivo a longo prazo. Para evitar quedas bruscas de pressão, que podem levar à hipotensão, a redução deve ocorrer de maneira gradual e constante. Nelson e Couto (2009) sugerem que a primeira parte do tratamento é diminuir gradativamente a ingestão de sal na dieta, apesar do mesmo citar que não há estudos que evidenciem a eficácia dessa redução. A restrição de $\mathrm{NaCl}$ nos alimentos pode ter um efeito contrário ao desejado ao estimular a ativação do SRAA, já que este sistema atua justamente na prevenção do desequilíbrio de sódio do organismo. Dessa forma, a associação do uso dos inibidores da ECA, ou dos antagonistas dos receptores de aldosterona ou angiotensina II, se torna indispensável quando a redução da ingestão de sal na dieta for instituída (BROWN, 2007). 
NOGUEIRA, T.Q. e POGGIANI, S.S.C. Hipertensão sistêmica associada à doença renal crônica, revisão de literatura. PUBVET, Londrina, V. 7, N. 1, Ed. 224, Art. 1484, 2013.

Nos casos onde a redução dos níveis de sódio da dieta não surtirem efeito, é indicado o uso de inibidores da ECA (iECA) em sua dose padrão. Se o animal está sendo medicado nesta dose, e mesmo assim, a pressão arterial permanece alta, sugere-se duplicar a dose do iECA que estava sendo previamente utilizada. O próximo passo para os animais que não estão respondendo aos protocolos anteriores, é indicar a associação de iECA com bloqueadores dos canais de cálcio, como por exemplo, a amlodipina. Como último protocolo para se reduzir a pressão arterial de um animal hipertenso, a combinação iECA, bloqueadores de canais de cálcio e hidralazina deve ser a base para o tratamento. Esses são os passos a se seguirem na abordagem terapêutica da hipertensão segundo indica a IRIS.

Segundo Ettinger e Feldman (2010), os iECA são fármacos capazes de bloquear o SRAA e portanto impedem a conversão de angiotensina I em angiotensina II. Esse mecanismo, no entanto, não é a única forma de atuação desta droga. Os iECA também promovem o aumento das bradicininas, além de reduzir temporariamente os níveis circulantes de aldosterona. Uma consideração importante citada por Lefebvre e Toutain (2004) é de que este medicamento bloqueia a conversão de angiotensina I em angiotensina II, porém não impede a produção de angiotensina II pelos outros mecanismos onde a ECA não está envolvida. Desta forma, os iECA não são capazes de suprimir completamente as concentrações de angiotensina II circulantes.

De acordo com Grauer e Greco (2000), um maior número de evidências tem indicado que o uso de iECA, além de reduzir a pressão arterial, também atua reduzindo a proteinúria e portanto retarda a progressão da DRC. Os iECA reduzem a pressão intraglomerular ao promover a vasodilatação principalmente da arteríola eferente (CARR e EGNER, 2009). Dessa forma, a pressão hidráulica nos capilares glomerulares diminui, o que contribui para a redução da proteinúria. Além disso, o uso desses medicamentos reduz o tamanho dos poros das células 
NOGUEIRA, T.Q. e POGGIANI, S.S.C. Hipertensão sistêmica associada à doença renal crônica, revisão de literatura. PUBVET, Londrina, V. 7, N. 1, Ed. 224, Art. 1484, 2013.

endoteliais dos capilares glomerulares, algo que também auxilia na atenuação da proteinúria (NELSON e COUTO, 2009).

Enalapril e benazepril são dois fármacos iECAs que possuem mecanismos de excreção diferentes. O enalapril é inteiramente eliminado do organismo pela excreção renal, enquanto o benazepril possui excreção renal e hepática. Em pacientes doentes renais crônicos, a meia-vida do enalapril é prolongada, pois a eliminação deste fármaco se torna prejudicada. Assim sendo, indica-se o uso de benazepril para tratamento da hipertensão arterial sistêmica em animais com doença renal crônica (BONAGURA e TWEDT, 2009).

Enquanto em cães os vasodilatadores mais recomendados são os iECAs, em felinos, são mais indicados os que atuam como bloqueadores dos canais de cálcio, como por exemplo a amloidipina (NELSON e COUTO, 2009). Estudos tem demonstrado que cerca de $50 \%$ dos gatos hipertensos não respondem de maneira eficiente ao tratamento com enalapril. Já em cães, o uso de bloqueadores dos canais de cálcio pode piorar a doença renal, apesar de diminuir, significativamente, a pressão arterial. Uma possível explicação para este efeito contrário é que este fármaco, nesta espécie, promove a dilatação preferencialmente da arteríola aferente, o que resulta em hipertensão glomerular (BONAGURA e TWEDT, 2009).

O mecanismo pelo qual os fármacos inibidores da ECA exercem seus efeitos benéficos também tem o potencial de causar efeitos indesejados como azotemia, hipotensão e hipercalemia. A diminuição da TFG ocasionada pelo uso de fármacos iECAs é o principal mecanismo que leva, nestes casos, à azotemia (ETTINGER e FELDMAN, 2010). A hipercalemia está geralmente associada à redução da TFG e à baixa produção de aldosterona conseqüente da inibição do SRAA. A hipotensão não é uma complicação muito freqüente do uso destes medicamentos, mas quando presente, pode se manifestar por períodos de letargia ou ataxia (NELSON e COUTO, 2009). 
NOGUEIRA, T.Q. e POGGIANI, S.S.C. Hipertensão sistêmica associada à doença renal crônica, revisão de literatura. PUBVET, Londrina, V. 7, N. 1, Ed. 224, Art. 1484, 2013.

A redução no débito cardíaco e na liberação de renina são os dois principais mecanismos pelos quais os beta-bloqueadores atuam na redução da pressão arterial sistêmica (BROWN e HENIK, 1998). O atenolol é um antagonista cardioseletivo, pois atua nos receptores beta-1 que se encontram principalmente no coração. O propanolol é considerado um antagonista não seletivo, pois além de atuar nos receptores beta-1, também atua nos receptores beta-2 localizados nos pulmões, o que pode levar à broncoconstrição e angústia respiratória. Dessa forma, o beta bloqueador de escolha para uso em animais hipertensos é o atenolol (BONAGURA e TWEDT, 2009).

A IRIS relata que o monitoramento freqüente dos pacientes sob tratamento anti-hipertensivo é essencial para evitar esses efeitos adversos. Após a estabilização do paciente, indica-se reavaliação do animal a cada pelo menos três meses. Segundo Brown e Henik (1998), esta avaliação deve envolver exame de fundo de olho, avaliação da doença primária, e mensuração da pressão arterial, do peso corporal e da concentração sérica de creatinina e eletrólitos.

Acierno e Labato (2005) consideram importante a diferenciação entre o animal que vivencia uma urgência hipertensiva e aqueles que vivenciam uma emergência hipertensiva. Os primeiros são aqueles que apresentam elevada pressão arterial sistêmica, porém não demonstram sinais clínicos referentes a esse aumento. O tratamento para redução da pressão, nesses casos, deve ser feito de forma gradual e controlada. Já os animais que estão em emergência hipertensiva, são aqueles que apresentam sinais clínicos atribuídos ao aumento da pressão arterial e requerem redução imediata da mesma, ou conseqüências letais podem acontecer.

Nesses casos, é indicado o uso de vasodilatadores como nitroprussiato e hidralazina, para promover rápida redução da pressão arterial. A amlodipina também é eficiente para gatos em emergência hipertensiva e o risco de induzir a hipotensão nestes animais é menor (NELSON e COUTO, 2009). Segundo Brown e 
NOGUEIRA, T.Q. e POGGIANI, S.S.C. Hipertensão sistêmica associada à doença renal crônica, revisão de literatura. PUBVET, Londrina, V. 7, N. 1, Ed. 224, Art. 1484, 2013.

Henik (1998), o nitroprussiato de sódio é um vasodilatador arterial e venoso cujo mecanismo de ação é promover a doação de óxido nítrico às células musculares lisas dos vasos. Esse fármaco deve ser administrado mediante taxa de infusão constante e geralmente não provoca taquicardia reflexa. É importante ressaltar que independente do tratamento de escolha para a emergência hipertensiva, deve-se escolher uma droga de longa duração para o controle da pressão arterial sistêmica a longo prazo (BROWN e HENIK, 1998).

\section{CONCLUSÃO}

A doença renal crônica é uma enfermidade freqüente na rotina veterinária que, apesar de ser de caráter progressivo e irreversível, quando diagnosticada precocemente, pode ter sua evolução consideravelmente retardada. A hipertensão, dentre as diversas alterações clínicas sistêmicas que a doença renal crônica pode causar, é uma das mais preocupantes tendo em vista sua íntima relação com a progressão da doença. É uma alteração comum nos pacientes nefropatas, porém devido à, muitas vezes, ausência de sinais clínicos específicos referentes a essa alteração sistêmica e, devido à necessidade de se portar alguns equipamentos de mensuração de pressão, muitas vezes a hipertensão é subdiagnosticada na rotina clínica. No entanto, devido à sua importância e relevância na progressão da DRC e as conseqüências que a mesma pode trazer, é sempre indicada a avaliação clínica da pressão arterial quando há suspeita de hipertensão.

\section{REFERÊNCIAS BIBLIOGRÁFICAS}

ACIERNO, M. J.; LABATO, M. A. Hypertension in Renal Disease: Diagnosis and Treatment. Clinical Techniques in Small Animal Practice. v.20, p.23-30, 2005. 
ATKINS, C. E.; GRAUER, G. F., Feline Chronic Kidney Disease and Systemic Hypertension. In: 2007 Proceedings of the Southern European Veterinary Conference. Barcelona, Espanha. Acessado

em 20 de Maio de 2011, disponível em: <
http://www.ivis.org/signin.asp?url=/proceedings/sevc/2007/grauer1/chapter.asp >

BARTOLOTTO, L. A. Hipertensão arterial e insuficiência renal crônica. Rev Bras Hipertens. v.15, n.3, p.152-155, 2008.

BOOMSMA, F.; TIPTON, K. F. Renalase, a cathecolamine-metabolising enzyme?. Journal of Neural Transmission. v.114, p.775-776, 2007.

BONAGURA, J. D; TWEDT, D. C. KIRK'S Current Veterinary Therapy XIV. 14 ed. St.Louis: Saunders, 2009.

BOURGOIGNIE, J. J.; HWANG, K. H.; ESPINEL, C.; KLAHR, S.; BRICKER, N. S. A Natriuretic Factor in the Serum of Patients with Chronic Uremia. The Journal of Clinical Investigation. v.51, p.1514-1527, 1972.

BOVEE, K. C. Effect of Chronic Hypertension on Renal Function in Dogs. In: $28^{\text {th }}$ Congress of the World Small Animal Veterinary Association, 2003, Bangkok, p.1-2.

BROWN, S. A. Sal, hipertensión y enfermedad renal crónica. Veterinary Focus. v.17, n.1, p.4546, 2007.

BROWN, S.; ATKINS, C.; BAGLEY, R. et al. Guidelines for the Identification, Evaluation, and Management of Systemic Hypertension in Dogs and Cats: 2006 ACVIM Consensus Statements. $J$ Vet Intern Med, 21, p.524-558, 2007.

BROWN, S. A.; HENIK, R. A. Diagnosis and treatment of systemic hypertension. Vet Clin. North. Am. v.28, p.1481-1493, 1998.

BUCKALEW, V. M.; GRUBER, K. A.; HenNeSSY, J. F. Trans Am Clin Climatol Assoc. v.95, p.8692, 1984.

BURANAKARL, C., ANKANAPORN, K., THAMMACHAROEN, S., TRISIRIROJ, M., MALLERATMONGKOL, T., THONGCHAI, P., PANASJAROEN, S. Relationships Between Degree of Azotaemia and Blood Pressure, Urinary Protein:Creatinine Ratio and Fractional Excretion of Electrolytes in Dogs with Renal Azotaemia. Veterinary Research Communications, Amsterdam, v. 31, p.245-257, 2007.

CAMPESE, V. T.; KU, E.; PARK, JEANIE. Sympathetic Renal Innervations and Resistant Hypertension. International Journal of Hypertension. v.2011, p.1-6, 2011.

CARR, A. P.; EGNER, B. Blood Pressure in Small Animals - Part 2*: Hypertension - Target organ damage, Heart and Kidney. European Journal of Companion Animal Practice, v.19, n.1, p.15, 2009.

CARVALHO, M. H. C.; NIGRO, D.; LEMOS, V. S.; TOSTES, R. de C. A.; FORTES, Z. B. Hipertensão arterial: o endotélio e suas múltiplas funções. Rev Bras Hipertens, v.8, n.1, p.76-88, 2001. 
CASTRO, M. C. M. de. Revisão/Atualização em Hipertensão Arterial: Hipertensão Arterial na insuficiência renal crônica. J. Bras. Nefrol. v.18, n.2, p.169-174, 1996.

CUnNingham, J. C. Tratado de Fisiologia dos Animais Domésticos. 2 ed. Rio de Janeiro: Guanabara Koogan, 1999.

DRAIBE, S. A.; CENDOROGLO, M. Tratamento conservador da insuficiência renal crônica. Revista Diagnóstico \& Tratamento. v.6, n.2, p.17-23, 2001.

EATON, D. C.; POOLER, J. P. Fisiologia Renal de Vander. 6 ed. Porto Alegre: Artmed, cap.7, p.123-135, 2006.

ETTINGER, S. J.; FELDMAN, E. C. Textbook of Veterinary Internal Medicine. 7aed. St.Louis: Saunders Elsevier, 2010.

ELLIOT, D.; LEFEBVRE, H. Insuficiencia renal crónica: importancia de la nutrición. In: Enciclopedia de la Nutrición Clínica Canina. Ithaca: Royal Canin, p.268-293, 2009.

FEITOSA, F. L. F. Semiologia Veterinária: a arte do diagnóstico. 2 ed. São Paulo: Roca, 2008.

GRAUER, G. F.; GRECO, D. S.; GETZY, D. M. et al. Effects of Enalapril versus Placebo as a Treatment for Canine Idiopathic Glomerulonephritis. J Vet Inter Med, v.14, p.526-533, 2000.

GReenberg, A.; Cheung, A. K.; COFfman, T. M.; FAlK, R. J.; JAnnetTe, J. C. Primer on kidney diseases. 5 ed. China: Saunders Elsevier, 2009.

GUYTON, A. C.; HALL, J. E. Tratado de Fisiologia Médica. 12 ed. Rio de Janeiro: Guanabara Koogan, 2010.

HEIMANN, J. C., VIDONHO, A. F. Jr; RUIVO, G. F. Mecanismos hipertensores em indivíduos portadores de nefropatia crônica. Rev. Bras. Hipertens., v.9, n.2, p.135-140, 2002.

JUNIOR, J. E. R. Doença Renal Crônica: Definição, Epidemiologia e Classificação. J Bras Nefrol. v.26, n.3, p.1-3, 2004.

KOSSI, M. El; BELLO, A. K.; HAMER, R.; NAHAS, A. M. El. Chronic Kidney Disease - Prevention of Progression and of Cardiovascular Complications. In:

LEES, G. E. Early diagnosis of renal disease and renal failure. Vet Clin Small Animal. v.34, p.867-885, 2004.

LEFEBVRE, H. P.; TOUTAIN, P. L. Angiotensin-converting enzyme inhibitors in the therapy of renal diseases. J. vet. Pharmacol. Therap., v.27, p.265-281, 2004.

LEVINSKY, NG. The renal kallikrein-kinin system. Journal of the American Heart Association. V.44, n.4, p.441-451, 1979.

LI, G.; XU, J.; WANG, P.; et al. Cathecolamines Regulate de Activity, Secretion and Synthesis of Renalase. Circulation Journal of the American Heart Association. v.117, n.10, p.1277-1282, 2008. 
LOSCALZO, J. Harrison's Cardiovascular Medicine. China: McGraw-Hill, cap. 37, p. 422-443, 2010.

MAGGS, D. J.; MILLER, P. E.; OFRI, R. Slatter Fundamentos de Oftalmología Veterinária. 4 ed. Barcelona: Elsevier, 2009.

MARTÍNEZ, P. P.; CARVALHO M. B. Participação da excreção renal de cálcio, fósforo, sódio e potássio na homeostase em cães sadios e em cães com doença renal crônica. Pesq. Vet. Bras., v.30, n.10, p.868-876, 2010.

MISHINA, M.; WATANABE, T. Development of Hypertension and Effects of Benazepril Hydrochloride in a Canine Remnant Kidney Model of Chronic Renal Failure. J. Vet. Med. Sci., v.70, n.5, p.445-460, 2008.

NELSON, R. W.; COUTO, C. G. Small Animal Internal Medicine. 4 ed. St. Louis: Mosby Elsevier, 2009.

RENNKE, H. G.; DENKER, B. M. Fisiopatologia Renal. 2 ed. São Paulo: Livraria Médica Paulista Editora LTDA, cap.2, p.50-60, 2009.

RIELLA, M. C. Príncipios de Nefrologia e Distúrbios Hidroeletrolíticos. $4^{a} e d$. Rio de Janeiro: Guanabara Koogan, cap.43, p.769-774, 2003.

RIGATTO, K. V.; BOHLKE, M.; IRIGOYEN, M. C. Sistema renina angiotensina: da Fisiologia ao Tratamento. Revista da Sociedade de Cardiologia do Rio Grande do Sul. n.03, p. 1-5, 2004.

SANTOS, M. M. dos; FRAGATA, F. da S. Emergência e Terapia Intensiva Veterinária em Pequenos Animais Bases para o atendimento hospitalar. São Paulo: Editora Roca Ltda, cap. 04, p. $91-98,2008$.

SILVA, G. V. da; GONÇALVES, A. B.; ORTEGA, K. C.; MION, D. Jr. Alterações renais na hipertensão arterial sistêmica. Revista da Sociedade de Cardiologia do Estado de São Paulo. v.18, n.2, p.175-182, 2008.

TRAPP, S. M.; VAILATI, M. C. F; MATSUBARA, B. B.; SCHWARTZ, D. R. Efeitos da angiotensina II no sistema cardiovascular. Archives of Veterinary Science. v.14, n.4, p.233-243, 2009.

WHITE, J. D.; MALIK, R.; NORRIS, J. M. Feline chronic kidney disease: Can we move from treatment to prevention?. The Veterinary Journal. v.190, n.3, p.317-322, 2011.

WORONIK, V. Hipertensão e doenças primárias renais. Revista HiperAtivo. v.5, n.4, p.253-260, 1998.

$\mathrm{XU}$, J.; LI, G.; WANG, P. et al. Renalase is a novel, soluble monoamine oxidase that regulates cardiac function and blood pressure. The Journal of Clinical Investigation. v.115, n.5, p.12751280, 2005.

ZATZ, R. ZATZ - Série Fisiopatologia Clínica - Fisiopatologia Renal (vol.2). São Paulo, Rio de Janeiro, Belo Horizonte: Atheneu, 2000. 